\title{
Delivering professional doctorate education: challenges and experiences during the COVID-19 pandemic
}

\author{
Matthew Tucker, Hannah Wilson, Claire Hannibal, Aileen Lawless, Zhouhua Qu \\ Liverpool Business School, Liverpool John Moores University, Liverpool, UK
}

\begin{abstract}
Professional Doctorates have similar attributes of a $\mathrm{PhD}$, but are arguably not as universally known. Moreover, professional doctorates have an added level of complexity, as students become scholarpractitioners by ensuring that they make a significant contribution to professional practice. However, professional doctorate education is often challenging due to the lack of research preparedness of professional doctorate students, who typically have been away from higher education for a number of years. Although these students may have built astute business mind sets, it could be argued that their approach to scholarly research is less so. So to achieve engaged scholarship that enables professional doctorate students to become scholar practitioners, it is crucial to create the correct learning environment. Using the Doctorate in Business Administration (DBA) at Liverpool Business School, UK, as a case study, the ability to deliver professional doctorate education is explored, and pertinently the challenge and experience of how the teaching and learning environment has transitioned since the COVID-10 pandemic is evaluated. Finally, key lessons are outlined as to how to design professional doctorate programmes that are resilient to disruptions to conventional teaching and learning practices.
\end{abstract}

\section{Introduction}

This paper takes a critical look at the nature of professional doctorate programmes, and the teaching and learning strategies required to ensure that they successfully deliver their intended purpose. The importance of students becoming scholar-practitioners is crucial to the success of professional doctorate programmes, and influences supervision styles and teaching techniques.

A case study professional doctorate programme is then introduced, critically discussing the teaching and learning strategies used at Liverpool Business School on their Doctorate in Business Administration (DBA) programme.

The paper provides pertinence by giving a unique insight into the strategies that were quickly adopted to ensure students received a seamless transition to online learning due to the COVID-19 pandemic. Finally, the paper concludes by providing the key lessons learned during this journey 


\section{The nature of professional doctorates}

Professional doctorates aim to make a significant contribution to the enhancement of an occupational or professional area through the application, development and testing of theoretical frameworks. They are required to show evidence that, by applying and testing existing and new theories, make a significant contribution to improvements or changes in organisation or working practices, which can be applied elsewhere.

Professional doctorates are distinctive in Higher Education as they are typically studied part time, whilst working in senior positions within an organisation. With a clear focus on developing professional practice those on a professional doctorate programme receive taught elements as well as supervisory support, therefore, provide additional complexity to student's experiences of professional doctorate programmes.

\section{Becoming a scholar-practitioner}

A professional doctorate graduate will be equipped with a mind-set that will enable them to ask questions in their organisation that make everyone else look at themselves and their work in a different way (Anderson and Gold, 2015). Moreover, researching professionals are also highly reflective and should practise reflection, have a strong sense of self and engage in reflexive research (ibid).

Being a scholar-practitioner comes with the responsibility of being able to use scholarly research methods in order to make an impactful contribution to professional practice. However, according to Allen et al. (2002), professional doctorates are often criticised due to the lack of research-orientated skills and it is common that they have been absent from higher education learning for a long period of time. Despite historic criticisms of the level of research rigour of executive doctoral programs, they are naturally research-driven with a clear application to professional practice.

Students often struggle to immediately refresh and grasp research concepts and applied research learning, due to their relative absence from higher education, and coupled with the high demands of the day-to-day business that they experience in the commercial world. It has been noted that effective teaching of research methods requires an informed understanding of the processes and obstacles in a given environment (Wagner et al., 2011). By developing a clear understanding of the learning environment to which students can flourish in learning research skills therefore becomes crucial.

With professional doctorate programmes approach of 'engaged scholarship' (Van de Ven and Jing, 2012), students are concerned with not only engagement with theory but the intersection with business issues. This poses issues for the practitioner researcher where there is a struggle in the legitimacy of research (Anderson, 2002). Having clear teaching and learning strategies to ensure this legitimacy of research is achieved is another crucial responsibility.

\section{Doctorate in Business Administration (DBA)}

DBA programme at Liverpool Business School is one of the most established Professional Doctorates in the University. Delivered through a blended learning approach over a fouryear period, the DBA is cohort-driven and consists of four one-week residential workshops, monthly virtual action learning sets, and supervision via distance learning. DBA candidates study part-time, and are likely to hold senior management positions.

Overall et al. (2011) highlights that a key challenge of doctoral supervision is how to balance the amount of guidance students receive to learn research skills, while giving them 
autonomy to become confident independent researchers. This challenged is considered by Gurr (2001) who investigates how to align supervisory styles with research student development. Gurr (2001) considers how supervisors should aim to transition over the research student's journey from providing appropriate supervision support that is dependent and hands-on, to a style that provides autonomy generation and students become competently autonomous and supervisors become more hands-off.

In the context of the DBA, cultural awareness is an added challenge in achieving these things, as the DBA profile mainly consists of international candidates. Engagement through appropriate teaching and learning strategies is therefore critical, and a blended learning approach enables candidates to learn together and to learn apart.

However, since the COVID-19 pandemic, learning together has become much more of a challenge, with all teaching and supervision being undertaken in a virtual capacity.

\section{Key strategies since COVID-19 pandemic}

A key thread running through the DBA programme is around reflection and questioning on what has been learnt together, and apart, in order to enhance engagement. This 'blending' enables candidates to move to a deeper level of learning, positively impact their engagement and participation, and ultimately inspire the research excellence of the programme.

Traditionally, this has predominantly been achieved and significantly enhanced through residential workshops in Liverpool, where DBA students are able to engage face-to-face with each other, as well as the DBA Faculty.

However, since March 2020 these physical activities have been unable to take place, and the whole ethos of the DBA programme was tested. Immediately, the programme team had to mobilise to using new virtual strategies to ensure that students would not lose the ability to learn together and learn apart. Four key strategies were introduced:

Asynchronous virtual learning material: traditionally learning material is delivered and provided face-to-face during residential workshops. However, since COVID-19, this has not been possible. As such, the programme team mobilised very quickly to provide learning virtual material in the form of video lectures, online activities and discussion forums, in an asynchronous format. Students would be advised to engage with the material in advance of the virtual workshops that they are timetabled for.

Virtual 'research cafe' workshops: research cafes are built on the assumption that people are wiser together than they are alone (The World Café, 2015). Research cafes are traditionally delivered face-to-face where students are divided in to small clusters on café style tables. The tables consist of a table cloth (for creative doodling), marker pens and post-it notes for a collaborative 'graffiti wall'. In clusters, students present on a particular research topic and have an open discussion, using prompts from moderators (usually programme staff). During the COVID-19 pandemic, these activities have been mobilised in to a virtual substitute, using breakout rooms and online software to create similar interactive mediums. For example, using online tools such as Mural, a digital workspace to visualise collaboration (Mural.co, n.d).

Virtual action learning sets: action learning is a key learning strategy on the DBA programme and very much aligns to the attributes of a scholar-practitioner. Action learning is a process of 'learning from concrete experience and critical reflection on that experience, through group discussion, trial and error, discovery and learning from one another' (ZuberSkerritt, 1993). Action learning sets provide a 'safe space' for members to practice questioning their assumptions and challenging their ways of thinking and doing (Corley and Thorne 2006). The COVID-19 pandemic has meant that effectively delivering action learning sets in a virtual capacity is extremely important. Wilson et al (2020) outline how 
the DBA programme has enhanced its ability to utilise technology for the virtual action learning sets. For example, by introducing mechanisms to keep a log of action learning sets through a multi-user collaboration tool. The tool enables students to log actions, questions, insights and reflections. This form of asynchronous VAL has been used for senior leaders on a management development programme, finding positive results for learning, behaviour change and outcomes (Waddill 2006).

\section{Conclusions and lessons learned}

This paper has outlined the nature of professional doctorates, their particularities and their similarities to wider doctoral education. It then provided critique on the importance of becoming a scholarly practitioner, and how shaping the write learning environment, and supervision style can get the most out of professional doctorate students. Finally, the paper presented the current mechanisms used at Liverpool Business School's DBA programme, and how their traditional teaching and learning strategies have had to adapt and mobilise virtually due to the COVID-19 pandemic.

The key lessons learnt from this experience is that it is important to ensure that teaching and learning strategies at doctoral level adequately align to the nature of the research student. In the context of the DBA, the programme team are aware of the challenges with students' research preparedness, the necessity to create impactful research for business practice, whilst learning in a collaborative and engaging research environment.

Although the virtual mechanisms that have put in place can never be a complete substitute to face-to-face delivery, they have been successful in ensuring that the programme team can maintain the ethos of the DBA programme: to learn together and learn apart.

\section{References}

1. L. Anderson, J. Gold, 'Becoming a Scholar-Practitioner' in Anderson, L., Gold, J., Stewart, J. and Thorpe, R. eds., A guide to professional doctorates in business and management. Sage, London (2015)

2. C.M. Allen, E.M. Smyth, M. Wahlstrom, Responding to the Field and to the Academy: Ontario's evolving PhD, Higher Education Research \& Development, 21 (2) 203 (2002)

3. C. Wagner, M. Garner, B. Kawulich, The state of the art of teaching research methods in the social sciences: Towards a pedagogical culture. Studies in Higher Education, 36(1) 75 (2011)

4. A.H. Van de Ven, R. Jing, Indigenous management research in China from an engaged scholarship perspective. Management and Organization Review, 8(1) 123 (2012)

5. G.L. Anderson Reflecting on research for doctoral students in education. Educational researcher, 31(7) 22 (2002)

6. N.C. Overall, K.L. Deane, E.R. Peterson, Promoting doctoral students' research selfefficacy: combining academic guidance with autonomy support, Higher Education Research \& Development, 30 (6) 791 (2011)

7. G.M. Gurr, Negotiating the "Rackety Bridge" — a Dynamic Model for Aligning Supervisory Style with Research Student Development, Higher Education Research \& Development, 20:1 81 (2001)

8. The World Café A Quick Reference Guide for Hosting World Café, The World Café Community Foundation, accessed from http://www.theworldcafe.com/wpcontent/uploads/2015/07/Cafe-To-Go-Revised.pdf (2015) 
9. Mural.co (n.d), About Us, accessed from https://www.mural.co/about-us

10. O. Zuber-Skerritt, Improving Learning and Teaching Through Action Learning and Action Research. Higher Education Research and Development, 12 (1) 45 (1993) 11. A. Corley, A. Thorne, Action Learning: Avoiding Conflict or Enabling Action. Action Learning: Research and Practice 3 (01) 31 (2006)

12. H. Wilson, M. Tucker, C. Hannibal, Z. Qu, Learning together, learning apart: integrated action learning through a socio-technical systems lens. Action Learning: Research and Practice, DOI: 10.1080/14767333.2020.1843403 (2020)

13. D. Waddill, Dewolfe Action e-Learning: An Exploratory Case Study of Action Learning Applied Online. Human Resource Development International 9 (2) 157(2006) 